\title{
O Contra-senso em Imagens *
}

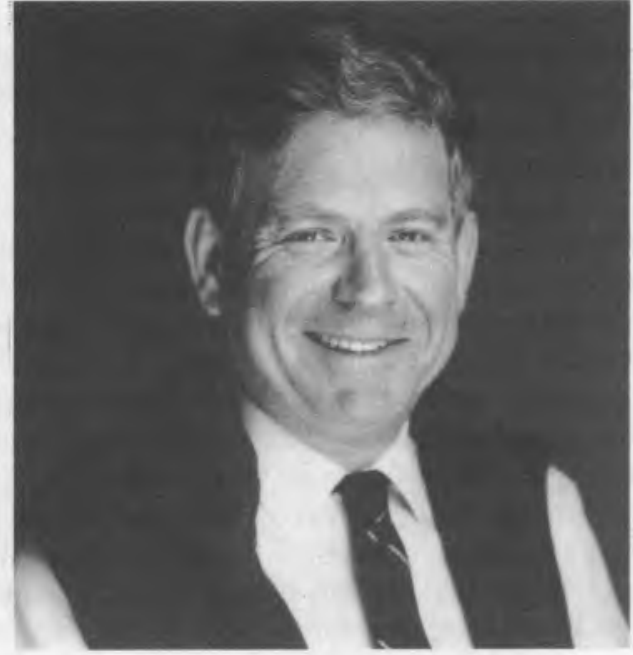

LASZLO (Pierre), Universitário. NASC. 15/8/38 em Alger. Filho de François Laszlo, Eng. hidráulico e de Madeleine Aczel. CAS. 15/2/62 com Martine Fayein (3 filhos: Sophie, Chloé, Aline). ESTUDOS. Liceus Champollion em Grenoble e Saint-Louis em Paris. Liceu franco-brasileiro no Rio/de Janeiro. Universidades de Grenoble e Paris. DIPLOMAS. Licenciatura em Ciências. Doutoramento em Ciências. CARREIRA. Assistente na Universidade de Paris (61/62), Investigador Auxiliar na Universidade de Princeton (EUA) (62/63), Mestre-Assistente na Universidade de Paris-Orsay (63/66). Professor-Assistente na Universidade de Princeton (66/70), Professor na Universidade de Liège (depois de 70), na Escola Politécnica (depois de 86). OBRAS. "Organic Spectroscopy» (1971) (tradução francesa, 1972); «Leçons de chimie» (3 vol. 1974); "Protons ans Ions Involved in Fast Dinamic Phenomena" (1978); "NMR of Newly Accessible Nuclei» (1983); "Cours de chimie organique» (1984); «Molecular Correlates of Biological Concepts» (1986); "Preparative Chemistry Using Supported Reagents» (1987). 150 artigos. CONDEC. Cavaleiro das Palmas Académicas, Oficial da Ordem de Léopold (Bélgica). DIST. Prémio trienal da Sociedade Química Belga (1980), Prémio dos sábios franceses fuzilados pelos alemães em 1940/44 (1981). PASSATEMPOS. Tradução de poemas de Pétrarca, música. Interessa-se pela história intelectual, pela ligação ciência-literatura. DESPORTOS. Sky, natação, ténis, squash, marcha. MEMBRO das Sociedades Químicas da Bélgica, França, Grã-Bretanha, EUA, Suíça, da Academia das Ciências de Nova Yorque.

\section{O texto}

Inserido no Cosmopolita ou Nova Luz Química (com um diálogo do Mercúrio, do Alquimista e da Natureza), de Jean Béguin (J. D'Houry, Paris, 1669, pag. 22-23) encontra-se um "Tratado do Sal", qualificado de "discurso em verso" e constituído por 24 versos sem rima. Ei-lo**:

Resolva então a sua pedra duma maneira conveniente, Não de um modo sofisticado;

Talvez seguindo o pensamento dos Sábios

4 Sem a ela juntar qualquer corrosivo;

Uma vez que não há qualquer outra água,

Que possa resolver a nossa pedra;

Excepto uma pequena fonte muito pura e muito clara,

8 Que deixa fluir de si própria,

O humor apropriado para a dissolução,

Mas ela está escondida de quase toda a gente,

Ela aquece tanto por si mesma,

12 Que consegue que a nossa pedra transpire lágrimas; Ela só precisa de um lento calor externo, É principalmente disto que se devem lembrar, Mas é ainda preciso que eu vos descubra uma outra coisa;

16 Que se não virem nenhum fumo negro por baixo, E uma mancha branca por cima,

A vossa obra não ficou bem feita,

Enganaram-se na dissolução da pedra.

20 Já assim sabiam interpretar este sinal, Mas se procederem como devem proceder Aperceber-se-ão que a nuvem negra,

Rapidamente se afundará,

24 Ao mesmo tempo que o espírito tomará a cor branca.

a Laboratoire de Chimie, École Polytechnique, 91128 Palaiseau Cedex, França.

* Traduzido e adaptado por Raquel Gonçalves, com o acordo do Professor Pierre Laszlo, de "La déraison en images»; Études françaises, 19, 2, pag. 64-80. A versão original contém uma Introdução e referências explicativas que foram suprimidas por motivos de paginação.

** Obtive este poema graças ao Prof. Jean-Paul Pittion, do Trinity College de Dublin, o qual me fez descobrir em Agosto de 1979 a biblioteca Marsh e a sua colecção Bouhereau, extremamente rica em livros de Química e Alquimia do sec. 17. Aqui lhe deixo o meu agradecimento em nome da nossa velha amizade. 
Esforçar-me-ei por analisar este breve texto sem ceder demasiado às duas tentaçōes a que se expõe o estudante de alquimia: traduzi-lo de modo totalmente positivista para a linguagem da nossa química moderna, com o perigo inerente de eclipsar o seu brilho interior; aplicar sem discernimento diversas técnicas da crítica literária, o que transformaria este verdadeiro texto (pré)-científico em literatura de pouco nível. Trata-se, na verdade, de um texto "tradicional"; e Jean Béguin, que publicou os Elementos de Química em 1647 em Rouen, diz ter traduzido o seu Cosmopolita do latim de um certo Sendivogius, autor cuja identidade permanece obscura. Não me debruçarei sobre a ilusória procura das suas fontes e tratarei o poema, tal como ele foi recolhido e transcrito por Jean Béguin em 1669, como um documento da história intelectual do séc. 17; e como uma amostra, preciosa pela sua rica concisão, da literatura da alquimia.

\section{Revelação dos paradoxos}

No centro deste poema reside uma imagem insólita: "[...] a nossa pedra transpire lágrimas".

Em relação a este eixo médio, o verso 12 , podem distinguir-se seis grupos cuja importância é grosso modo equivalente: os quatro primeiros versos especificando o estilo imperativo do discurso; os cinco versos seguintes que se ligam, pelo menos aparentemente, a uma referência ("uma pequena fonte muito pura e muito clara'); os três seguintes que retomam o cariz hermético ("Mas ela está escondida de quase toda a gente'). Depois, na segunda parte do poema, após a quebra dramática do verso 12 , os versos 13 e 14 reatam o estilo prescritivo dum protocolo experimental; enquanto que os cinco versos que se seguem (15-19) tratam de outra referência concreta ("fumo negro por baixo/mancha branca por cima'), tem um valor duplamente simbólico, uma vez que é responsável pelo procedimento adoptado. Os cinco últimos versos, (20-24), finalmente, parecem uma repetição dos precedentes, com a retomada do tema hermenêutico ("Já assim sabiam interpretar este sinal" ") até à consumação da "cor branca".

Retornemos ao verso 12: "ela (leia-se: "uma pequena fonte muito pura e muito clara") consegue que a nossa pedra transpire lágrimas" ". A pedra, que é o objecto da obra, é, como se vê, concebida como qualquer coisa orgânica; o que está de acordo com outra confusão entre natureza orgânica e mineral que é a seguinte: a pequena fonte "que deixa fluir de si própria" (v. 8) e que se "aquece tanto por si mesma" (v. 11).

Existe aqui um duplo sentido, químico, o duma reacção exotérmica na transpiração da pedra e moral ou tropológico, o duma agonia, tal como a da Paixão de Cristo, preâmbulo indispensável a uma apoteose. $\mathrm{O}$ poema inscreve-se entre os dois polos da dissolução, morte aparente, já que ele transforma o sólido num líquido, e o da sublimação final, que converte - dualismo do corpo e do espírito - " uma matéria corporal, homogénea, grosseira, terrestre, fixa, numa matéria subtil e leve, líquida, suave, volátil a aerífera, que sobe no ar'"*. Tal sublimação é classificada segundo os alquimistas de "volatilização do fixo".

Esta manifestação final do espírito responde à exigência de revelação, no "Tratado do Sal", do que é oculto "[...] ela está escondida de quase toda a gente" (v. 10); "Mas é ain-

\footnotetext{
* (Guillaume Salmon), Dicionário Hermético, L. D'Houry, Paris, 1695 (Gutenberg Reprints, 1979) pag. 191-192.
}

da preciso que eu vos descubra uma outra coisa" (v.15); "Já assim sabiam interpretar este sinal"' (v. 20).

Como porcurar a hermenêutica, o sentido por detrás das manifestações visíveis, passar do registo materialista à significação simbólica da Alquimia? O texto obriga-nos a uma atitude paradoxal, uma lógica dos contrários.

\section{Uma outra lógica}

Uma vez que o nosso poema é também " discurso do método: "Resolva então a sua pedra duma maneira conveniente" (v. 1); "É principalmente disto que se devem lembrar" (v. 14); "Mas se procederem como devem proceder", (v. 21). Mas um "discurso do método" manifestamente insuportável ao autor do "Discurso do Método": Descartes sobre os alquimistas e os seus discursos confusos, incoerentes e contraditórios sempre se mostrou sarcástico. $\mathrm{Na}$ sua carta de 23 de Novembro de 1646 ao Marquês de Newcastle *, por exemplo, ataca-os nestes termos:

\begin{abstract}
" Subscrevo totalmente o juízo de Vossa excelência sobre os químicos, e creio que eles nada mais fazem do que dizer palavras não comuns, com o fim de se mostrarem sabedores do que não sabem [...] na minha opiniāo, os seus sal, enxofre e mercúrio não diferem entre si mais do que os quatro elementos dos filósofos, nem mais do que a água difere do gelo, da espuma e da neve: penso que todos os corpos são feitos duma mesma matéria e que não há mais nada que faça a sua diversidade a não ser as pequenas partes da matéria que compõem uns se rearranjarem doutro modo, ou se agruparem diferentemente, do que as que compõem os outros".
\end{abstract}

"Eles nada mais fazem do que dizer palavras não comuns...", exclama Descartes. É também assim o caso do autor do nosso texto. Desde que se esmiuce um pouco, as contradições aparecem. Exemplos: 1. "ela aquece tanto por si mesma" / "ela só precisa de um lento calor externo"' (v. 11 e 13). 2. ("A pequena fonte) aquece tanto [...] que a nossa pedra transpira lágrimas' (v. 11 e 12). $3^{\circ}$ no verso 24 , o branco é qualificado de "cor"'. As ambiguidades também: "ela só precisa de um lento calor externo" 'refere-se à pedra, ou à pequena fonte?

Na passagem supracitada, Descartes explica a diversidade no aspecto macroscópio dos objectos e das substâncias pelas diferenças geométricas na forma ou no arranjo dos constituintes microscópicos. A esta lógica atomista, o nosso poema alquímico opõe uma lógica holística e orgânica, a de Ouroboros, e da pequena fonte autónoma! (" uma pequena fonte [...] que deixa fluir de si própria" (v. 8); "ela aqueça tanto por si mesma"' (v. 11). Este totalitarismo não deixa de evocar o poder absoluto, o do Rei-Sol, sobre o qual Louis Marin** mostrou que se exercia pela confusāo entre a realidade e os signos com que se revestia***.

Coexiste com o monismo da substância um dualismo das aparências: o texto desenvolve-se por uma dinâmica de antíteses.

\footnotetext{
* Descartes, Obra. Cartas, Paris, Gallimard, "La Pléiade", 1941, pag. 1012-1013.

** L. Marin, O Retrato do Rei, Paris, Minuit, "Le Sens commun", 1981. *** Cl. Rosset, "L'effet royal", Crítica, 417, 120-129 (1982).
} 
"maneira conveniente" / "modo sofisticado" (v.1 e 2)

"fonte [...] muito clara" / "escondida de quase toda a gente" (v. 7 e 10)

"fumo negro", / "mancha branca" (v. 16 e 17)

"por baixo"" / "por cima" (v. 16 e 17)

"nuvem negra" " "a cor branca" (v. 22 e 24)

Como escreveu Michel Butor * " "os textos (alquímicos) acumulam desafios ao princípio da não-contradição". O nosso texto, aparentemente inofensivo e curioso, estimula-nos, no entanto, desde o seu título: "Tratado do Sal'. Seguramente, este pequeno poema não pretende ser um tratado; e, pelo menos na aparência, não se debruça sobre o sal!

\section{A transgressão das regras do discurso clássico}

Ao que parece, um texto alquímico como este violaria os ideais cartesianos do pensamento claro e distinto. Em geral, a literatuta alquímica do séc. 17, longe de utilizar o corpo tradicionalmente considerado como clássico, Pascal, Racine, Madame de La Fayette, funciona como seu complementar. Ela é o contra-exemplo da Lógica de Port-Royal. Esta análise, porém, tem de ser cuidadosa. Em resumo, a literatuta alquímica, longe de se opor ponto por ponto à "grande" literatura clássica do séc. 17, partilha com ela o que eu designaria, de uma maneira totalmente anacróni$\mathrm{ca}$, pelo termo, atribuído a Bachelard, de "racionalismo aplicado". Com uma excepção importante: no discurso da alquimia, os significantes permutam sem cessar; enquanto que no discurso clássico, a única permuta lícita é a do significante com o significado. Pelo contrário, o discurso da alquimia aparenta-se com o discurso jurídico, no qual o ideal clássico serve de máscara e de contrapeso. Explicitemos estas complicadas afirmações.

Um racionalismo aplicado: o ideal dos autores do séc. 17, com a submissão à razão,

"Nós que às regras da razão nos comprometemos..."***

uma razão que procura a verdade no estudo da natureza,

"Que a natureza seja então o vosso único estudo"'**

desconfiando dos falsos semblantes da imaginação ou do amor-próprio e inscrevendo-se numa tradição sagrada (a Bíblia, os Padres da Igreja) ou consagrada (a Antiguidade), como se pode constatar lendo Pascal ("...eu troço dos autores que não são contrários à tradição,"***) ou dos prefácios de Racine.

Nada a reter de tudo isto para ser aplicado ao discurso alquímico, oh surpresa! A distinção, de facto crucial, encontra-se na álgebra da circulação dos termos do discurso, da forma como a Lógica de Port-Royal, entre outras, está formalizada. Como diz o Padre Jesuíta a Pascal, no Quarto Provincial: "Substituir a definição pelo definido não altera o sentido do discurso" ". O que de algum modo se anticipa ao cálculo das proposiçōes.

* M. Butor, Reportório, Paris, Minuit, 1960.

** Boileau, Arte Poética, III.

*** Pascal, Quarto Provincial, Paris, ed. F. Brunetière, Hachette, 1910, (ed. de 1947).
É ai que se encontra a clivagem, pois que no discurso alquímico, como vimos, há um constante resvalar de um definido para outro. Tal como no discurso jurídico, no discurso político que utiliza o discurso clássico que nos foi transmitido por Madame de Sévigné. Cardeal de Retz e Saint-Simon, vemos evoluir impenetráveis mónadas (o Rei, Monsieur, Condé, etc.) em relação aos quais os cortesãos avaliam as posições e as opiniões e admiram os seus menores caprichos ou iras para lhes insuflar as suas próprias opiniōes, atitudes e acçōes. É um mundo opaco onde se movem silenciosamente criaturas gigantes, frias e monstruosas, em redor das quais os mexericos da Corte devem andar numa roda-viva, para que ele possa sobreviver. O delírio interpretativo deste mundo (para algo extrair da incomunicabilidade total, da incompreensão profunda entre os âmagos destas personagens políticas) parece-me perfeitamente isomorfo do delírio interpretativo do Adepto que deseja compreender as palavras ou um texto do seu Mestre-de-Alquimia.

Um contra-senso em imagens, com imagens coloridas, fortes, cheias, tal como a imagem da fonte, é o que vamos agora desenvolver.

\section{A fonte de piedade*}

"Uma vez que não há qualquer outra água”, diz o nosso texto, "[...] uma pequena fonte muito pura e muito clara" (v. 5 e 7). Esta água de purificação, que associa frequentemente à pureza e à limpidez uma terceira qualidade, a subtileza, é de primordial importância para os alquimistas.

Basile Valentin, por exemplo, assim se dirige ao Adepto "Para ti [...] que ousas pesquisar a fonte da nossa Obra" **, para descobrir "a fonte de todas as mercês"**. Que fonte mágica é esta que, imaginário ou real, se adorna de todas as virtudes? Podemo-nos atrever a identificá-la com o mercúrio "puro, subtil, claro, tão brilhante como uma pequena fonte, transparente como o cristal e sem qualquer sujidade",**.

O pendente simbólico é o de uma ascése purificadora, dum retorno às origens, ao núcleo primordial intacto e brilhante duma alma límpida, vivendo numa esplendorosa claridade paradisíaca, no momento bendito da Redenção. Esta água purificadora, se a conseguirmos encontrar, é inesgotável: a água da profunda fonte $[. .$.$] nunca acaba**. E -$ justificação daquilo que eu avancei a propósito da circulação dos enunciados alquímicos, como seja a identificação desta fonte com o Mercúrio Filosófico - a Pedra torna-se fonte, ela própria transpira um líquido, um orvalho, até mesmo lágrimas como se diz no verso 12,0 que exprime um tema tradicional, o do carácter vivo (e vivificador) da $\mathrm{Pe}$ dra. Assim nos indica um outro tratado, contemporâneo do de Jean Béguin*** " há dois aspectos na Pedra: o conheci-

\footnotetext{
* Se o leitor deseja uma ilustração para além do texto, examine uma reprodução do quadro de Jérôme Bosch, no Museu do Prado, O Jardim das Delícias. Este quadro mostra uma graciosa fonte rosa, no eixo da figura de Cristo pintado da mesma cor, assente sobre um montículo de lodo onde brilham gemas cristalinas e pérolas, magna primordial, matéria prima do alquimista. Esta fonte é para o pintor, mais do que uma fonte, é um vaso litúrgico, coração ou receptáculo do sangue de Cristo, o Santo-Graal.

** Basile Valentin, As Doze chaves da filosofia, trad., introd, notas e explicações das imagens por E. Canseliet, Paris, Minuit, 1956. B. Valentin é uma figura mítica ou apócrifa do séc. 15, associada a Paracelso pelos seus adeptos.

* * * O Fio de Ariadne. Para entrar com segurança no labirinto da Filosofia Hermética, Paris, L. d'Houry, 1695.
} 


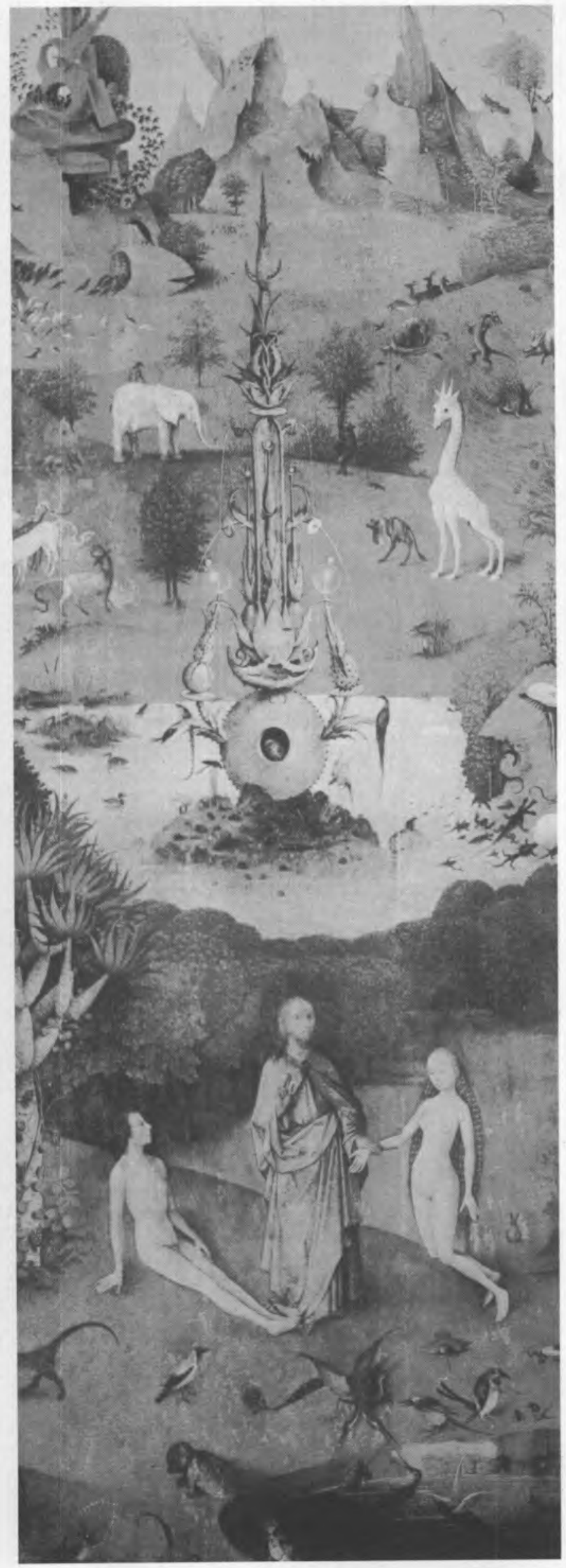

Jerôme Bosch, «O Jardim das Delícias» (pormenor) Museu do Prado, Madrid mento imediato de que é o mercúrio; e a matéria remota que é a água, uma vez que ela tinha sido água antes de ser mercúrio".

\section{Um fogo secreto}

Para que se realize a operação, física e espiritual, evocada pelo nosso texto, é suficiente uma pequena força exterior ao sistema, servindo de auxiliar: "É principalmente disto que se devem lembrar"' (v. 14).

\section{"Ela só precisa de um lento calor externo"}

(por lento, entenda-se mantido durante largo tempo, a um nível relativamente fraco). Para que serve este "lento calor externo" do verso 13 ? O verso 11, "Ela aquece tanto por si mesma", descreve apropriadamente o que um químico actual qualificaria de imediato de reação exotérmica, mas que, para os alquimistas, se revestia de um profundo significado.

Os versos 11 e 13 contrastam nas espécies de calor: um lento e externo, tal como o calor das cinzas "sobre o qual o ovo Filosofal se conserva, e que tem um calor doce proveniente do vapor temperado da lamparina"*; outro aquecimento violento e interno da Pedra em contacto com o seu líquido de dissolução que ela própria gera, de modo suicida. Este segundo fogo, qualificado pelos alquimistas de fogo natural, segregado pela Pedra e secreto, é igualmente qualificado, com frequência, de água seca. Trata-se de um "operador universal" $* *$, absolutamente indispensável à à Obra, e que no séc. 16 Gerhard Dorn assim descrevia**:

"um fogo vaporoso, nebuloso, durável, capaz de permitir digestão e cozedura, que não faz chama, que não realiza volatilizações nem ebulições, mas que está fechado e rodeado de ar, que não se consome nem se destrói, mas que altera e penetra. [...] um fogo corrosivo que recobre de algum modo o ar, por cima do nosso recipiente, de uma nuvem [...] (um) orvalho do caos.

Este fogo, o do Sol segundo nos diz o Dicionário Hermético***, é o da energia cósmica, de um plasma pulsátil de batimento harmonioso, regular, animador do universo. É através deste fogo que se aquece a Pedra, que passa a transpirar lágrimas, de acordo com verso 12 do nosso texto.

\section{Cristologia}

A pequena fonte do poema evoca a fonte da vida, de que nos fala Basile Valentin, na sua "Primeira Chave" ****:

Mas, meu amigo, previna-se diligentemente, de modo a que a fonte da vida seja encontrada pura e clara. Nenhuma água estranha deve ser misturada com a nossa fonte, que nenhum malogro aconteça e que do peixe saudável não nasça uma serpente.

Nestes momentos, o texto alquímico parece utilizar um discurso teológico. O tema cristão é trazido para primeiro plano. Parece inclusive escutar-se o Requiem de Mozart:

* (Guillaume Salmon), op. cit., pag. 62.

** Bernard Gorceix, Alquimia, Paris, Fayard, 1980.

*** (Guillaume Salmon), op. cit.

**** Basile Valentin, op. cit., pag. 109. 
Rex tremendae majestatis

Qui salvandos salvas gratis

Salva me, fons pietatis!

O poema incita à dissolução (do corpo) como preparação da exalação da alma e do espírito. E, no seu eixo médio, onde se adivinham múltiplos sentidos, a expressão "transpire lágrimas" deve ser tomada como uma alusão evidente ao Golgatha. Transpirar lágrimas: o terceiro termo, ausente neste "Tratado do Sal" que descreve a parte de elaboração alquímica denominada "Obra ao Negro", o outro humor trazido à evidência por esta conjugação do suor e das lágrimas, é o sangue de Cristo. O objectivo da Obra é a elevação final do vermelho do sangue de Cristo, que se segue à mortificação da Obra ao Negro, na qual o sofrimento tem o carácter de iniciação. Neste estádio da Obra ao Negro, o sangue não aparece explicitamente, e o vermelho encontra-se dissimulado. Tudo se passa como no quadro "São Jerónimo penitente" de Georges de La Tour, no Museu de Grenoble: o quadro não mostra os ferimentos que o santo se infligiu, e que o espectador adivinha, dolorosos, no seu ombro esquerdo, em segundo plano. Nesta tela,o santo é-nos apresentado de perfil, numa postura sofredora e ambígua, o joelho esquerdo em terra, a perna direita semi-flectida semi-distendida: penitente, por um lado, e mundano, por outro, evocando curiosamente um cavaleiro. Na sua mão esquerda segura firmemente uma cruz simples. Da mão direita pende um pedaço de corda cuja extremidade está vermelha de sangue. $O$ outro elemento vermelho deste quadro é um pano onde se enrola, meio-nu, São Jerónimo. No solo, algumas pedras; e, de pé quase miraculosamente, como se sobre uma estante (ausente, é claro), um grande livro, o das Escrituras, aberto ao meio, e do qual o santo, na sua meditação, inclinado sobre a cruz, se desviou.

Nesta tela, tal como no poema alquímico que examinámos, a realidade está por assim dizer suspensa: a personagem está isolada dos seus semelhantes; quase nu e numa espécie de deserto; as suas feridas não são visíveis; etc..

Georges de La Tour oganizou na tela uma rede de analogias e de inversôes. Analogias: o santo está só com o seu sofrimento, à semelhança de Cristo na cruz; a sua penitência lembra a de Cristo; a ponta da corda evoca os pregos e a coroa de espinhos. Inversões: o quadro mostra o que é invisível: a penitência; a renúncia; a piedade.

De modo paralelo convém entender que a "pequena fonte" do poema alquímico:

\section{- não tem nascente exterior \\ — não dá uma água qualquer \\ - não se encontra numa praça pública, mas sim no nosso foro íntimo}

Assim, uma regra de leitura do poema podia ser: adoptar o sentido oposto, uma vez que se trata de um discurso paradoxal, invertido. Aplica-lo-emos mais tarde.

Porquê uma tal alteração da forma e do estilo do discurso, não só no poema alquímico como também no quadro de La Tour e em muitas outrás obras clássicas*?

Não será este o local indicado para desenvolver a resposta a esta questão. Limitar-me-ei a algumas indicaçôes: o heliocentrismo generalizado do séc. 17 em França, o do Rei-Sol, organiza ligaçōes entre esferas (o Rei, a sociedade,

\footnotetext{
* J. D. Lyons, Romanic Review, 72, 383-400 (1981); S. Meleuc, Langa-
} ges, 13, 84, Março 1969. a língua, as instituições públicas, a natureza animada e a natureza inanimada). Num tal panorama, a dinâmica destas passagens ou conecções irradia uma ideologia aumentativa da glória do Rei; isto é, literalmente, da luz que ele emite; o que implica também o desaparecimento dos sectores de sombra, de ambivalência ou de ambiguidade.

Por entre as subversões do discurso, ou da ideologia oficial e régia - que se caracteriza como tautologia e focalização no Rei -, encontram-se subversões por alteração da forma e do estilo do discurso*; através das perturbações da palavra, que recorrem ao irracional; subversões paradoxais, por reforço quase anómalo a equivalências e conecções (exemplo: o antropomorfismo de La Fontaine, ao pôr os animais a falar); $\mathrm{e}$ ainda as subversões religiosas - as do jansenismo; do pietismo de Madame Guyon; de Fénelon; de Pascal.

Com efeito, em oposição surda ao discurso omnipresente e totalitário do Rei-Sol, encontramos o cristianismo e todas as desconecções que lhe são próprias: independência entre a esfera civil e a esfera religiosa ("dar a César..."); separação do humano do divino; a sociedade humana é uma imagem imperfeita da reunião dos bem-aventurados; os idiomas dos homens (pós-babilónicos) são também imagens imperfeitas duma comunicação infinitamente fácil; a figura humana é uma imagem imperfeita de Deus.

A convergência do discurso alquímico e do discurso cristão não é pois acidental, e assemelha-se porventura a uma aliança táctica!

\section{Permutações}

Discurso paradoxal, diríamos nós, uma apresentação que interfere com a lógica, inverte a perspectiva. É assim o discurso alquímico, se acreditarmos de novo em Basile Valentin ("'Da grande Pedra dos Antigos Sábios")**:

Faz com que o que está no alto fique em baixo e o que é visível, invisível, palpável, impalpável e de novo, faz com que o que está em baixo fique em cima, do invisível, o visível, do impalpável, o palpável. Isto é tudo arte $[\ldots]$

Do mesmo modo, o texto do nosso poema, repartido entre oposições semelhantes - conveniente/sofisticado (v. 1 e 2); esconder / descobrir (v. 10 e 15); interno / externo (v. 10 e 13); por cima / por baixo (v. 17 e 16); negro / branco (v. 16 e 17, 22 e 24) - , organiza uma circulação da leitura entre os quatro elementos primordiais: a Água alia-se ao Fogo (vermelho) para originar, passando pelas trevas da melancolia, o Ar, rapidamente até à brancura luminosa; é no meio de operações realizadas sobre a Pedra, que participa o elemento Terra.

Como nos explica Guillaume Salmon***:

Pôr o que está por cima em baixo e o por baixo em cima, é modificar as naturezas, isto é os elementos, ou fazer seco o que é húmido, e o que é corpo fazer-se espírito.

Tomemos um exemplo: experimentemos uma operação de inversão sistemática. Que se obtém? Qualquer coisa deste género:

* J. D. Lyons, op. cit.; S. Meleuc, op. cit.

** Basile Valentin, op. cit., pag. 95.

*** (Guillaume Salmon), op. cit., pag. 40. 
bem no fundo, a cor branca;

no alto, uma emanação (ou espírito) negro;

um forte calor interno;

a partir da dissolução de um líquido concretiza-se uma pedra;

ela arrefece por si própria;

ela aparece finalmente ao Adepto;

ela emite uma pequena fonte;

é preciso juntar um agente corrosivo;

e assim teremos coagulado a pedra.

Constatemos simplesmente que uma tal inversão, tão brutal quanto simplista,pode funcionar.

$\mathrm{O}$ discurso alquímico estabelece, provavalmente, toda uma combinatória. Será preciso esperar por Leibniz para que o pensamento racional experimente, por seu lado, toda a virtude geradora de novos conceitos, dum pensamento simbólico deste tipo operando por manipulações estritamente regidas por leis.

\section{Este poema é um texto pré-científico}

O poeta, assim que considera a "pequena fonte", seja ela qual for, incita-nos a observar este objecto com um olhar muito particular. Com efeito, este objecto escapa às regras do nosso mundo comum. Entendo que aí existe a conceptualização pré-científica de um objecto - que mais tarde, no séc. 18 , se tornará microscópica desde o momento em que, com Buffon, Needham, Spallanzani, Dalton, Lomonossov, etc. o pensamento científico se tornou atomista. Este texto pode igualmente ser considerado como científico atendendo à sua axiomática (procura da verdade); pelo seu carácter de protocolo, simultaneamente transmissão de um saber e papel maioritário conferido à experimentação; pela importância atribuída às observações (da destilação da pedra; da aparição de um fumo negro, por exemplo); e pelo seu carácter preditivo (se fizer isto, sucederá aquilo). Para além disso não convém esquecer a alquimia, pela importância que aí toma a noção de transformação que revitalizou toda a ciência ocidental.

Com o risco de parecer exagerar, direi que as exclusões e selecções que abundam na forma do poema são também testemunho do seu carácter anunciador do método científico dos tempos modernos: focalizar a atenção sobre um fenómeno natural, dele excluindo o resto do mundo.

Pelo contrário, este texto foge da ciência, pelo menos àquela que é definida (de uma forma imperfeita, sem dúvida) pelos nossos critérios científicos, uma vez que nâo integra qualquer explicação dos fenómenos observados; porque se pode e deve ler com duplo significado; e por causa da flutação que daí resulta, devido às palavras não terem uma acepção única e precisa entre significante e significado.

Nos finais do séc. 17 princípios do séc. 18 , assistiu-se em França a uma proliferação de livros e opúsculos alquímicos: este incremento, sugiro, pode ter sido uma resposta à submissão do espírito a uma religião de Estado, esvaziadora das consciências individuais, após a Revogação do Édito de Nantes. Ela foi talvez o acompanhamento e o sintoma de uma crise intelectual a partir da qual nasceu a ciência moderna.

Com efeito, a que atribuir uma tal vaga de alquimia no momento exacto em que o seu carácter científico era posto em dúvida? O exemplo, que nos é contemporâneo, de $O$ Des- pertar dos Mágicos* ajuda-nos um pouco. Quando a ciência triunfa, é tentador atacar-lhe vivamente as suas fronteiras, denunciando as insuficiências do racionalismo. Era isto que levava Descartes a considerar o discurso alquímico como não científico e errado, até mesmo perverso.

\section{Aplicabilidade dos instrumentos das ciências humanas aos textos científicos}

Existe uma separação entre textos ditos científicos e textos ditos literários. Uma tal demarcação é, por certo, largamente arbitrária. Eu vejo-a, no entarito, fundamentada numa prática: os primeiros respondem a uma questão; os segundos propõem uma certa visão do mundo. O objectivo do estudo de um texto, pelo lado literário, é uma incorporação: a escrita de um comentário faz-se na margem de outro texto literário; ele visa a reconstituição, por via indirecta do dito texto, duma totalidade; e propõe-se compreender uma mensagem entre outras. Do lado da ciência, os objectivos são outros: fazer entrar o texto estudado na história da ciência, sendo esta concebida como uma totalidade em via de realização; representar a tradição e a inovação; descobrir um novo jogo, uma redistribuição dos conceitos, numa cronologia na qual se fixam os limites temporais de estabilidade ou de modificação.

A semelhança entre estas duas actividades encontra-se na sua multiplicação: a crítica literária é totalizante, quer ao nível do próprio texto, quer ao nível da sua base de construção. A história das ciências é também totalizante, quer interna quer externamente.

As diferenças, porém, são patentes. Se o comentário ao texto literário pode ser, ele próprio, literatura, o do texto científico distingue-se frequentemente de ciência. $\mathrm{O}$ idealismo da crítica literária recorre à pluralidade das mensagens. $\mathrm{O}$ positivismo da história (ou da filosofia) das ciências procura uma mensagem unívoca, tenta reconstituir o que ela realmente diz. Estas oposições fazem-nos retroceder a uma distinção fundamental. A crítica literária herdou a tradição hermenêutica de interpretação de textos sagrados (Bíblia); e ela teria tendência a reintegrar o sagrado na literatura pela via indirecta da estética (Mallarmé). $\mathrm{O}$ estudo do texto científico (que resolve um problema, responde a uma questão) situa-se inteiramente no registo do profano, cujos objectivos são muito raramente apologéticos; a religiāo é posta entre parênteses; e os trabalhos que emanam do interior de um conjunto de crenças (ou paradigma) visam somente a supressão racionalista do carácter sagrado da natureza.

Esta distinção essencial, do sagrado e do profano, tem muitas consequências. O vaticínio (Sigogne; Antonin Artaud; Raymond Russel) aparece por seu lado como lirismo puro, e como alienação do conhecimento científico. O equivalente ao estudo de um texto literário, é talvez a análise de um período científico. Inversamente, o risco na aplicação dos instrumentos da crítica literária ao estudo dos textos científicos - que explica provavelmente o sectarismo generalizado entre os historiadores das ciências - é sobrepor ao "texto" científico noções subjectivas, anacrónicas, com o perigo de distorcer o seu verdadeiro sentido; e acompanhar-se de ignorância de outros textos científicos, anteriores ou contemporâneos, que permitem explicar aquele que se estuda.

Como responder a esta objecção? Ou adicionando ao discurso dos historiadores das ciências o que ainda não foi di-

\footnotetext{
* L. Pauwels e J. Bergier, O Despertar dos Mágicos, Venda Nova,
} Bertrand, 1987 (12\% ed.). 
to por meio de uma estratégia cruzada ou, e é essa a minha escolha, partindo do não-dito do texto científico. É neste ponto que eu vou insistir para terminar.

\section{O estudo dos textos alquímicos como modelo para a crítica literária}

Voltemos ao nosso texto. Explorámos a pluralidade dos seus sentidos:

Mortificar o corpo para exaltar o espírito.

(regra mística)

A morte de Cristo prefigura o Julgamento Final, os Justos para a Paraíso e os Maus para o Inferno.

(teologia)

No princípio era a água;

a terra emergiu das águas;

a terra aqueceu,

e a água rolou sobre a terra;

a luz separou-se das trevas.

(cosmogonia)

Em contacto com um solvente, o sólido (a pedra) sofre uma reacção, ou transição de fase, fortemente exotérmica, com formação de um líquido, se- guida de um desprendimento de vapores brancos com formação de um precipitado ou de fumos negros mais pesados.

(química)

Acelerar o coração para estimular o cérebro.

(iatroquímica)

Pelo contrário, a leitura de um texto alquímico como se se tratasse de um texto literário, exige a manutenção da união dos diversos significados. Num texto-Proteu, que se altera de leitura em leitura, as evidências que acompanham os vários pontos de vista sucedem-se.

A crítica literária negligenciou até agora a literatura alquímica*. Esta foi abordada com sucesso por outras disciplinas: história intelectual (Alexandre Koyré); mitologia comparada (Mircea Eliade); psicanálise (Carl Jung). É, no entanto, um domínio rico, terreno e húmus simultaneamente, que me parece ao mesmo nível dos métodos e das preocupações da crítica contemporânea. Este foi um ensaio para o demonstrar.

* Um encontro foi, todavia, organizado sobre este assunto em Junho de 1977 pela Sociedade do séc. 17. Os textos correspondentes podem ler-se em Dix-septième siècle, 120, 1978 e Australian Journal of French studies, 12, 1, 1981.

\section{Convite à Reflexão}

\section{Os Defeitos do Realismo: a química do átomo}

Em vez de se acrescentar directamente ao electrão propriedades e forças, vai-se-lhe acrescentar números quânticos e, segundo a repartição destes números, deduzir-se-á a repartição dos lugares destes números, deduzir-se-á a repartição dos lugares dos electrões no átomo e na molécula. Apreenda-se bem a súbita volatilização do realismo. Aqui, o número torna-se um atributo, um predicado da substância... assim, a Química, que foi durante muito tempo a ciência substancialista por excelência, vê o conhecimento das suas matérias volatilizar-se cada vez mais. Se julgamos o objecto segundo as provas da sua objectividade, devemos dizer que o objecto se matematiza e manifesta uma aproximação singular da prova experimental e da prova matemática. $\mathrm{O}$ abismo metafísico entre o espírito e o mundo exterior, tão intransponível para os metafísicos intuitivos imediatos, aparece menor para uma metafísica discursiva que tenta seguir os progressos científicos. Pode-se mesmo conceber um verdadeiro deslocamento do real, um depuramento do realismo, uma sublimação metafísica da matéria. A realidade transforma-se, primeiro, em realismo matemático, depois o realismo matemático dissolve-se numa espécie de realismo das probabilidades quânticas. O filósofo que segue a disciplina dos quanta - la schola quantorum - aceita pensar todo o real na sua organização matemática, melhor ainda, habituar-se a medir metafisicamente o real pelo possível, numa direcção estritamente inversa do pensamento realista. Portanto, exprimamos esta dupla supremacia do número por uma fórmula polémica: a substância química não passa da sombra de um número.

Gaston Bachelard, "O Novo Espírito Científico"
CARBONO, de carbo, ou carvão; pré-histórico. Existe em várias formas naturais: diamante, grafite e carvão. A sua variedade infindável de compostos é uma fonte indispensável ao fabrico de produtos de uso diário, como o "nylon" e a gasolina, os perfumes e os plásticos, graxas, DDT e TNT.

AZOTO ou NITROGÉNIO, de nitron e génos, ou gerador de nitro (salitre); descoberto em 1772; é um gás que constitui cerca de $78 \%$ do ar. O azoto entra na composição do "gás hilariante", do TNT, dos fertilizantes e dos aminoácidos (as unidades estruturais das proteínas). 


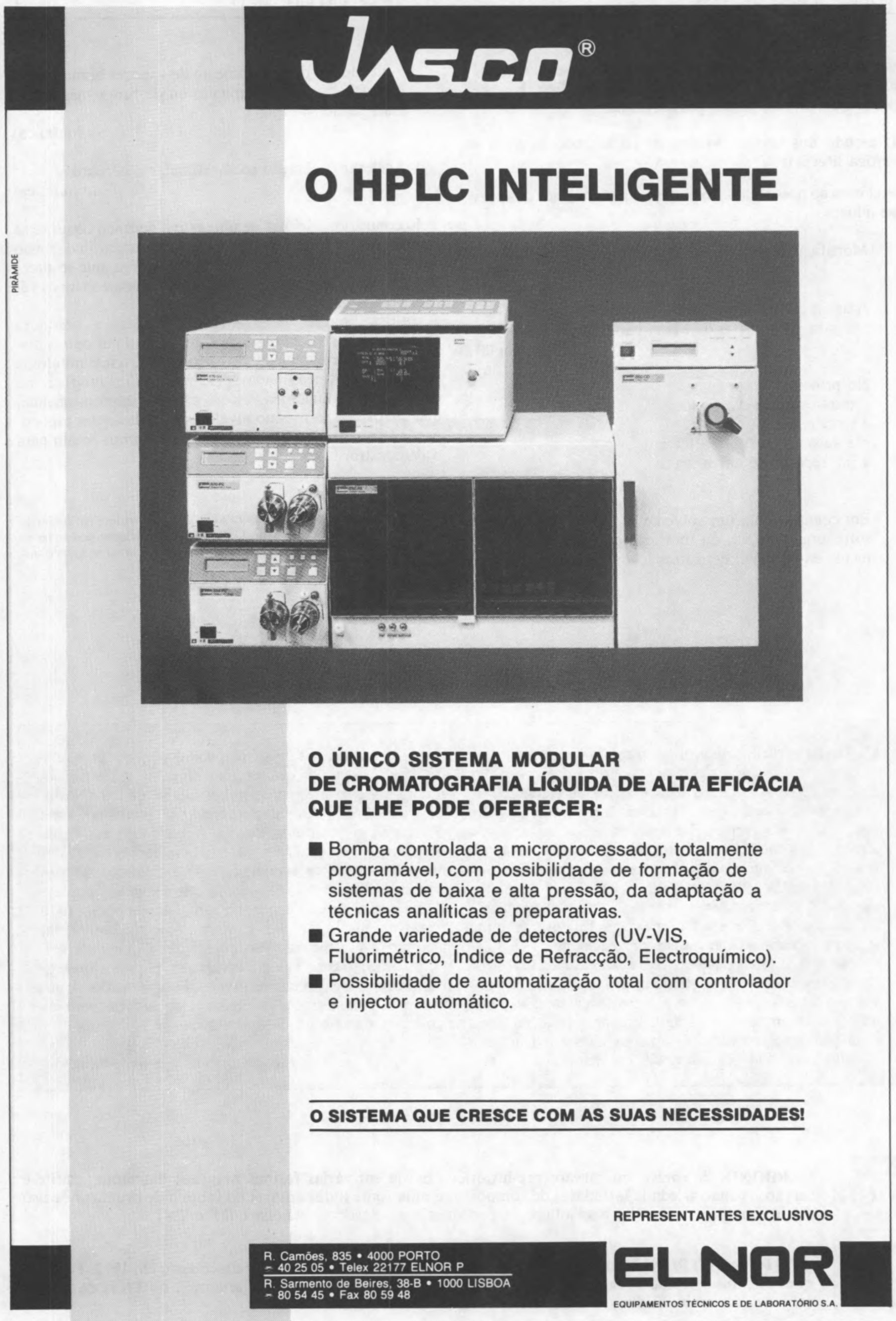

